\title{
Duopoly price competition with limited capacity
}

\author{
A. Bërdëllima ${ }^{1}$ D \\ Received: 4 April 2019 / Accepted: 13 December 2020 \\ (c) The Author(s) 2021, corrected publication 2021
}

\begin{abstract}
We study a variation of the duopoly model by Kreps and Scheinkman (1983). Firms limited by their capacity of production engage in a two stage game. In the first stage they commit to levels of production not exceeding their capacities which are then made common knowledge. In the second stage after production has taken place firms simultaneously compete in prices. Solution of this sequential game shows that the unique Cournot equilibrium outcome as in Kreps and Scheinkman is not always guaranteed. However the Cournot outcome is still robust in the sense that given sufficiently large capacities this equilibrium holds. If capacities are sufficiently small, firms decide to produce at their full capacity and set a price which clears the market at the given level of output.
\end{abstract}

Keywords Capacity · Cournot · Duopoly competition · Nash equilibrium · Sequential game

Mathematics Subject Classification D40 - D43 - L10 - L11 · L13 · L20

\section{Introduction}

In their seminal paper Kreps and Scheinkman (1983) showed constructively that solutions to oligopoly games depend not only on the strategic variables employed but also the context of the game in which these variables are used. To make their point they consider a duopoly game which takes place in two stages. In the first stage producers decide independently and simultaneously how much they will produce, and this production takes place. Then in the second stage these levels of production are made common knowledge and they simultaneously compete in prices in a Bertrand-like market.

This research was in part supported by DAAD fellowship. I thank Gerald Pech and the anonymous referees for their helpful comments in improving the quality of the paper.

A. Bërdëllima

berdellima@math.tu-berlin.de

1 Institut für Mathematik, Technische Universität Berlin, 10623 Berlin, Germany 
Under certain assumptions about the demand and cost of production the Cournot outcome is the unique equilibrium outcome of this game. In this note our aim is to study the equilibrium of this game under the constraint that in the first stage firms cannot commit to levels of production beyond a certain capacity. After these levels cost of production becomes prohibitively high. We are able to show the robustness of Kreps and Scheinkman's result in the sense that if capacities for both firms are sufficiently large then Cournot outcome is still supported as the unique equilibrium of the game. However in general such an equilibrium is not guaranteed to exist. This lets for possibilities of other equilibria in the game. The case when only one firm's capacity can support Cournot output level is more complicated. It is not clear whether there is a pure strategy in output and prices for this situation. However under the assumption that a pure strategy in quantities exists in the first stage and capacities are sufficiently small we show that firms produce at their full capacities. Afterwards in the second stage firms set a price which clears the market at the given level of output.

Such a model of duopoly with limited capacity is not the first in the literature. Indeed studies for characterizing equilibria in markets where competing firms are limited by their capacities of production date back to at least Edgeworth (1925) who has shown that in general markets with capacity constraints do not have an equilibrium. However other works in later years have proved that an equilibrium in terms of mixed strategies, be these in prices or quantity commitments, does in fact exist. For example Beckmann (1965) has given a mixed strategy equilibrium as a solution for a duopoly model suggested by Shubik (1959). A related work is found in Levitan and Shubik (1972) in which they examine a duopoly model with linear demand where firms limited by their capacity constraints simultaneously compete in prices. They indicate that there is a range over which the price is expected to fluctuate, a point made earlier by Edgeworth. The argument goes as follows, if one firm sets its price equal to zero then it will sell up to its capacity limit. In case the capacity is smaller than the market demand at zero prices then the other firm will be faced with a positive residual demand and therefore could act as a monopoly on its residual demand and make strictly positive profits. If one allows for a loose dynamic argument the former firm could increase its price from zero to just under that of monopoly price that the opponent firm would set. This could lead to a period of price undercutting that in turn would give rise to a range over which the price would fluctuate. This is what Levitan and Shubik (1972) term as the Edgeworth cycle. Levitan and Shubik's model was then generalized by Osborne and Pitchik (1986) where demand is continuous and decreasing. In a certain way a similar departure from Kreps and Scheinkman (1983) is made by Hviid (1990), Hviid (1991) with uncertain demand. However in these works in a way or another capacities are chosen by firms instead of being imposed as constraints (see also Jara-Moroni 2011). This means that capacity is a strategic variable. In our model the strategic variable is production quantity precommitment. It is noteworthy that in the Kreps-Scheinkman game the Cournot ourcome is sensitive to the demand rationing rule. Davidson and Deneckere (1986) argue that if the rationing follows the opposite proportional extreme to the efficient rule as in Kreps and Scheinkman, or any rule strictly between these two extremes then the Cournot outcome is no longer an equilibrium for the game. They assume zero costs at the first stage. On a positive side, Madden (1998) showed that under the assumptions that 
demand is uniformly elastic and all costs are sunk at the first stage, then with any rationing mechanism between the efficient and proportional extremes the Cournot outcome is the unique equilibrium of the game. This remedied the rationing rule "anomaly" of Davidson and Deneckere. In a different work Deneckere and Kovenock (1996) characterize the set of Nash equilibria in a price duopoly where firms have limited capacity, but in which unit costs of production up to capacity may differ. More recent literature related to duopoly competition has been generally focused on variations of duopoly models with uncertain demand. For instance Gabszewicz and Poddar (1997) and de Frutos and Fabra (2011) study the role of demand fluctuations in price competition and capacity utilization. For a duopoly model where capacity constraints appear in the inputs of production we refer to Nie and Chen (2012).

This work is organised as follows. In Sect. 2 we describe the model. Then in Sect. 3 some preliminary results are presented, in particular Theorem 1 which is a generalization of a classical result of Levitan and Shubik (1972). These are necessary for the main contributions in Sect. 4 namely Theorem 2 which characterizes the equilibrium when capacities of both firms are sufficiently large and Theorem 3 for sufficiently small capacities.

\section{The model}

There are two identical firms producing perfectly substitutable goods for which the aggregate market demand function is given by $P(x)$ (price as a function of quantity $x$ ) and $D(p)=P^{-1}(p)$ (demand as a function of price $p$ ). Let $k_{i}, k_{j} \geqslant 0$ denote the capacity of production of firm $i$ and $j$ respectively.

Assumption $1 P(x)>0$ on some interval $(0, X)$, on which it is twice-continuously differentiable, strictly decreasing, and log-concave in $x$ i.e. $\log \left(P\left((1-t) x_{1}+t x_{2}\right)\right) \geqslant(1-t) \log P\left(x_{1}\right)+t \log P\left(x_{2}\right)$ for all $x_{1}, x_{2} \in(0, X)$ and $t \in[0,1]$. Suppose further $\lim _{x \uparrow X} P(x)=0$.

Assumption 2 Both firms face the same cost of production $b: \mathbb{R}_{+} \rightarrow \mathbb{R}_{+}$which is twice- continuously differentiable, convex, and satisfies $b(0)=0$ and $b^{\prime}(0)>0$. To avoid trivialities, $b^{\prime}(0)<P(0)$ (production at some level is profitable).

Assumption 3 Firms $i$ and $j$ can produce up to their capacities $k_{i}, k_{j} \geqslant 0$ respectively. After these levels cost of production becomes prohibitively high.

For a given pair of prices $\left(p_{i}, p_{j}\right)$ we define the residual demand of the firm $i$ in the following way. If $p_{i}<p_{j}$ customers first buy from firm $i$ and when its capacity $k_{i}$ is finished customers turn to firm $j$. In case $p_{i}=p_{j}$ the market demand is shared between the two firms proportionally to their capacity levels provided total capacity $k_{i}+k_{j}$ is not less then the market demand. Otherwise both firms exhaust their capacities. Under these assumptions the residual demand $q_{i}^{d}$ for firm $i$ is 


$$
q_{i}^{d}= \begin{cases}D\left(p_{i}\right) & p_{i}<p_{j} \\ \max \left\{\delta_{i} D\left(p_{i}\right), D\left(p_{i}\right)-x_{j}\right\} & p_{i}=p_{j} \text { where } \delta_{i}=\frac{x_{i}}{x_{i}+x_{j}} \\ \max \left\{0, D\left(p_{i}\right)-x_{j}\right\} & p_{i}>p_{j}\end{cases}
$$

The revenue for firm $i$ is

$$
R_{i}\left(p_{i}, p_{j}\right)= \begin{cases}\min \left\{p_{i} x_{i}, p_{i} D\left(p_{i}\right)\right\} & p_{i}<p_{j} \\ \min \left\{p_{i} x_{i}, \max \left\{\delta_{i} p_{i} D\left(p_{i}\right), p_{i}\left(D\left(p_{i}\right)-x_{j}\right)\right\}\right\} & p_{i}=p_{j} \\ \min \left\{p_{i} x_{i}, \max \left\{0, p_{i}\left(D\left(p_{i}\right)-x_{j}\right)\right\}\right\} & p_{i}>p_{j}\end{cases}
$$

and profit $\Pi_{i}=R_{i}\left(p_{i}, p_{j}\right)-b\left(x_{i}\right)$. In the first stage firms commit to levels of production $x_{i} \leqslant k_{i}, x_{j} \leqslant k_{j}$ which are then made common knowledge. In the second stage after production has taken place firms simultaneously compete in prices.

\section{Preliminary results}

We follow standard terminology from game theory, see (1991, Fudenberg and Tirole). Let $\left(x_{i}, x_{j}\right)$ be any commitment that firms make in the first stage of the game not exceeding capacity levels i.e. $x_{i} \leqslant k_{i}$ and $x_{j} \leqslant k_{j}$. It is of essential interest to investigate types of equilibria in prices for a given pair $\left(x_{i}, x_{j}\right)$. It is known due to Levitan and Shubik (1972) that a mixed strategy equilibrium in prices exists for the case when the market demand $D(p)$ is linear. Their result can be extended for a general demand function $D(p)$ not necessarily linear. A mixed strategy equilibrium in prices requires certain price intervals over which firms randomise. Let $I=\left[p_{i}, \overline{p_{i}}\right]$ and $J=\left[p_{j}, \overline{p_{j}}\right]$ be such intervals of firm $i$ and firm $j$ respectively. Randomization is described by probability distributions functions. To this end denote by $\Phi_{i}(p)$ and $\Phi_{j}(p)$ the corresonding distributions over these intervals $\left(\Phi_{i}(p):=\operatorname{Pr}\left(p_{i} \leqslant p\right)\right)$. Distributions are assumed to be differentiable. For the existence of a nondegenerate mixed equilibrium we must have $I \cap J \neq \phi$ otherwise one would have $\Phi_{i}(p)=0$ $\left(\Phi_{i}(p)=1\right)$ for all $p \in J$ whenever $\Phi_{j}(p)=1\left(\Phi_{j}(p)=0\right)$ for all $p \in I$. As a mapping we can write $\left(\Phi_{i}, \Phi_{j}\right): I \times J \rightarrow[0,1] \times[0,1]$. Define $A:=I \cap J$ and $p_{L}:=\max \left\{p_{i}, p_{j}\right\}, p_{H}:=\min \left\{\overline{p_{i}}, \overline{p_{j}}\right\}$ and suppose $A$ has nonempty interior i.e. $p_{L}<p_{H}$. The $\overline{s e t} A=\left[p_{L}, p_{H}\right]$ is known as the set of active strategies. The probability of a tie is zero since $\operatorname{Pr}\left(p_{i}=p_{j}\right)=\int_{p_{j}}^{p_{j}} d \Phi_{i}=0$.

Theorem 1 Let $\left(x_{i}, x_{j}\right)$ be any subgame. Then there exists a unique set of active strategies $A=\left[p_{L}, p_{H}\right]$ and mixed equilibrium $\left(\Phi_{i}, \Phi_{j}\right)$ in prices $p \in A$ given by

$$
\Phi_{i}(p)=1-\frac{R^{-1}\left(-p_{H}^{2} D^{\prime}\left(p_{H}\right)\right)}{p} \text { and } \Phi_{j}(p)=\frac{p D(p)+p_{H}^{2} D^{\prime}\left(p_{H}\right)}{p D\left(p_{H}\right)+p p_{H} D^{\prime}\left(p_{H}\right)}
$$

where $R(p)=p D(p)$ and $p_{H}$ satisfies the implicit equation $p_{L} D\left(p_{L}\right)=-p_{H}^{2} D^{\prime}\left(p_{H}\right)$. 
Proof For a given pair of strategies $\left(\Phi_{i}(p), \Phi_{j}(p)\right)$ the expected profits of firm $i$ is

$$
\mathbb{E} \Pi_{i}=\left(1-\Phi_{j}(p)\right) \min \left\{p x_{i}, p D(p)\right\}+\Phi_{j}(p) \min \left\{p x_{i}, \max \left\{0, p\left(D(p)-x_{j}\right)\right\}\right\}-b\left(x_{i}\right) .
$$

Without loss of generality we let $x_{i} \geqslant x_{j}$ and assume that $x_{i}>D(p), \forall p \in A$. One could simplify (2)

$$
\mathbb{E} \Pi_{i}=p\left(D(p)-\Phi_{j}(p) \min \left\{D(p), x_{j}\right\}\right)-b\left(x_{i}\right) .
$$

Under the assumption $x_{i}>D(p), \forall p \in A$, profits of firm $j$ would be

$$
\mathbb{E} \Pi_{j}=p\left(1-\Phi_{i}(p)\right) \min \left\{D(p), x_{j}\right\}-b\left(x_{j}\right) .
$$

Notice that $\Phi_{i}(p)=1$ can not be an active strategy ${ }^{1}$. Therefore $p_{H}=\bar{p}_{j}$ implying $\Phi_{j}\left(p_{H}\right)=1$. For $\Phi_{j}\left(p_{H}\right)$ to be an active strategy we must have $x_{j}<D\left(p_{H}\right)$. This condition yields

$$
\mathbb{E} \Pi_{i}=p\left(D(p)-\Phi_{j}(p) x_{j}\right)-b\left(x_{i}\right)
$$

and

$$
\mathbb{E} \Pi_{j}=p\left(1-\Phi_{i}(p)\right) x_{j}-b\left(x_{j}\right) .
$$

Without loss of generality let the active strategy set coincide with the set $A$. At $p=p_{H}$ the profits for firm $i$ are $\mathbb{E} \Pi_{i}=p_{H}\left(D\left(p_{H}\right)-x_{j}\right)-b\left(x_{i}\right)$. Since $p_{H}$ is the upper end of the range of active strategies then the derivative of $\mathbb{E}_{i}$ with respect to $p$ at $p_{H}$ must be nonpositive. This implies

$$
\left.\frac{\partial \mathbb{E} \Pi_{i}}{\partial p}\right|_{p=p_{H}} \leqslant 0 \text { equivalently } D\left(p_{H}\right)-\Phi_{j}\left(p_{H}\right) x_{j}+p_{H}\left(D^{\prime}\left(p_{H}\right)-\Phi_{j}^{\prime}\left(p_{H}\right) x_{j}\right) \leqslant 0 .
$$

$D^{\prime}\left(p_{H}\right)$ exists and it is well defined because by assumption $P(x)$ is differentiable and strictly monotone implying $D(p)=P^{-1}(p)$ with $p=P(x)$ is also strictly monotone and differentiable. Moreover $\Phi_{j}\left(p_{H}\right)=1$ requires $\Phi_{j}^{\prime}\left(p_{H}\right)=0$ since $\Phi_{j}$ is a cumulative distribution function. Therefore (7) reduces to

$$
D\left(p_{H}\right)+p_{H} D^{\prime}\left(p_{H}\right) \leqslant x_{j}
$$

On the other hand from (5) we obtain

$$
\Phi_{j}(p)=\frac{p D(p)-\mathbb{E} \Pi_{i}-b\left(x_{i}\right)}{p x_{j}}
$$

which must have a non-negative derivative at $p=p_{H}$ as it is a distribution function. This means

\footnotetext{
1 An active strategy of a firm is such that the expected payoff of the other firm is strictly positive.
} 


$$
\left.\frac{\partial \Phi_{j}}{\partial p}\right|_{p=p_{H}} \geqslant 0 \text { equivalently } \frac{D^{\prime}\left(p_{H}\right)}{x_{j}}+\frac{\mathbb{E} \Pi_{i}+b\left(x_{i}\right)}{p_{H}^{2} x_{j}} \geqslant 0 .
$$

Using (5) and $\Phi_{j}\left(p_{H}\right)=1$ we obtain

$$
D\left(p_{H}\right)+p_{H} D^{\prime}\left(p_{H}\right) \geqslant x_{j} .
$$

Then inequalities (8) and (10) imply

$$
D\left(p_{H}\right)+p_{H} D^{\prime}\left(p_{H}\right)=x_{j}
$$

from which we obtain

$$
\mathbb{E} \Pi_{i}=p_{H}\left(D\left(p_{H}\right)-D\left(p_{H}\right)-p_{H} D^{\prime}\left(p_{H}\right)\right)-b\left(x_{i}\right)=-p_{H}^{2} D^{\prime}\left(p_{H}\right)-b\left(x_{i}\right) .
$$

At $p_{L}$ profits for firm $i$ are $\mathbb{E} \Pi_{i}=p_{L} D\left(p_{L}\right)-b\left(x_{i}\right)$. By definition of the mixed strategy equilibrium; the mixing strategy of each firm would make the other firm indifferent to playing the lowest from the highest bid in the range of active strategies. Therefore at these two different bids payoff must be the same, i.e. $p_{L} D\left(p_{L}\right)=-p_{H}^{2} D^{\prime}\left(p_{H}\right)$. Let $R(p)=p D(p)$ denote the revenue as a function of price $p$. By Assumption $1 P(x)$ is positive, strictly decreasing, log-concave and twice differentiable in $x$ on the interval $(0, X)$. It follows that $D(p)=P^{-1}(p)$ is positive, strictly decreasing, it satisfies $D^{\prime}(p)+p D^{\prime \prime}(p) \leqslant 0$ and it is twice differentiable in $p$ on the interval $(0, P(X))$. Therefore the function $R(p)$ is strictly concave on the interval $(0, P(X))$ since $R^{\prime \prime}(p)=2 D^{\prime}(p)+p D^{\prime \prime}(p)<0$. Condition (11) means $R^{\prime}\left(p_{H}\right)>0$ implying $R(p)$ is strictly increasing on the interval $\left[0, p_{H}\right]$. Then $\left.R^{-1}\right|_{\left[0, p_{H} D\left(p_{H}\right)\right]}$ exists and satifies $R^{-1}(p D(p))=p$ for all $p \leqslant p_{H}$. This determines an implicit equation of $p_{L}$ in terms of $p_{H}$ as

$$
p_{L}=R^{-1}\left(-p_{H}^{2} D^{\prime}\left(p_{H}\right)\right)
$$

From (6) we get

$$
\Phi_{i}(p)=1-\frac{\mathbb{E} \Pi_{j}+b\left(x_{j}\right)}{p x_{j}}=1-\frac{p_{L} x_{j}-b\left(x_{j}\right)+b\left(x_{j}\right)}{p x_{j}}=1-\frac{p_{L}}{p}=1-\frac{R^{-1}\left(-p_{H}^{2} D^{\prime}\left(p_{H}\right)\right)}{p} .
$$

Similarly from (5) we obtain

$$
\Phi_{j}(p)=\frac{D(p)}{x_{j}}-\frac{\mathbb{E} \Pi_{i}+b\left(x_{i}\right)}{p x_{j}}=\frac{D(p)}{x_{j}}-\frac{p_{L} D\left(p_{L}\right)-b\left(x_{i}\right)+b\left(x_{i}\right)}{p x_{j}}=\frac{D(p)}{x_{j}}-\frac{p_{L} D\left(p_{L}\right)}{p x_{j}} .
$$

Substituting (11) and the implicit equation $p_{L} D\left(p_{L}\right)=-p_{H}^{2} D^{\prime}\left(p_{H}\right)$ then we rewrite (15) finally as

$$
\Phi_{j}(p)=\frac{p D(p)+p_{H}^{2} D^{\prime}\left(p_{H}\right)}{p D\left(p_{H}\right)+p p_{H} D^{\prime}\left(p_{H}\right)}
$$


Now we show this mixed equilibrium in prices is unique. Let $\tilde{A}:=\left[\tilde{p}_{L}, \tilde{p}_{H}\right]$ be another active set of strategies and $\tilde{\Phi}_{i}, \tilde{\Phi}_{j}$ the corresponding distributions for firm $i$ and firm $j$ respectively. From analysis above we have at $p=\tilde{p}_{H}$

$$
D\left(\tilde{p}_{H}\right)+\tilde{p}_{H} D^{\prime}\left(\tilde{p}_{H}\right)=x_{j} \quad \text { equivalently } \quad R^{\prime}\left(\tilde{p}_{H}\right)=x_{j} .
$$

On the other hand from (11) follows $R^{\prime}\left(p_{H}\right)=R^{\prime}\left(\tilde{p}_{H}\right)$. Since $R$ is strictly concave then $\tilde{p}_{H}=p_{H}$. Morevoer $\tilde{p}_{L}=R^{-1}\left(\tilde{p}_{L} D\left(\tilde{p}_{L}\right)\right)=R^{-1}\left(-\tilde{p}_{H}^{2} D^{\prime}\left(\tilde{p}_{H}\right)\right)=R^{-1}\left(-p_{H}^{2} D^{\prime}\left(p_{H}\right)\right)=p_{L}$ hence $\tilde{p}_{L}=p_{L}$. Therefore the active set of strategies $\tilde{A}=A$. That $\tilde{\Phi}_{i}=\Phi_{i}$ and $\tilde{\Phi}_{j}=\Phi_{j}$ follows easily from (14) and (16).

Another preparatory result we need is the following lemma.

Lemma 1 Let $\left(x_{i}, x_{j}\right)$ be a subgame and let $x^{*} \in[0,+\infty)$ be the solution of the equation

$$
x^{*} P^{\prime}\left(2 x^{*}\right)+P\left(2 x^{*}\right)-b^{\prime}\left(x^{*}\right)=0
$$

If $\max \left\{x_{i}, x_{j}\right\} \leqslant x^{*}$ then a pure strategy in prices $p_{i}=p_{j}=P\left(x_{i}+x_{j}\right)$ is supported in the second stage of the game. Note that $x^{*}$ is known as the Cournot level of output.

Proof It is clear that neither firm wants to put a lower price as otherwise they will get strictly lower profits. Assumption $\max \left\{x_{i}, x_{j}\right\} \leqslant x^{*}$ implies $x_{j} \leqslant x^{*}$. Let $p:=P\left(x_{i}+x_{j}\right)$. Suppose that firm $i$ contemplates to put a higher price $\tilde{p}>p$. Then its profit would be

$$
\tilde{\Pi}_{i}=\min \left\{\tilde{p} x_{i}, \max \left\{0, \tilde{p}\left(D(\tilde{p})-x_{j}\right)\right\}\right\}-b\left(x_{i}\right)=\max \left\{0, \min \left\{\tilde{p} x_{i}, \tilde{p}\left(D(\tilde{p})-x_{j}\right)\right\}\right\}-b\left(x_{i}\right)
$$

Let $\quad \tilde{x}_{i}:=D(\tilde{p})-x_{j}$. Law of demand $D(\tilde{p})<D(p)$ implies $\tilde{x}_{i}<x_{i}$. So $\tilde{\Pi}_{i}=\tilde{p} \tilde{x}_{i}-b\left(x_{i}\right)$. The condition $\lim _{x \uparrow X} P(x)=0$ implies the existence a point point $m_{i}\left(x_{j}\right) \in\left(0, X-x_{j}\right)$ that maximizes $\Pi_{i}\left(x, x_{j}\right)=x P\left(x+x_{j}\right)-b(x)$. From the first order condition we get

$$
P\left(m_{i}\left(x_{j}\right)+x_{j}\right)+m_{i}\left(x_{j}\right) P^{\prime}\left(m_{i}\left(x_{j}\right)+x_{j}\right)-b^{\prime}\left(m_{i}\left(x_{j}\right)\right)=0 .
$$

On the other hand since $x_{j} \leqslant x^{*}$ then log-concavity of $P$ implies

$$
\frac{P^{\prime}\left(m_{i}\left(x_{j}\right)+x_{j}\right)}{P\left(m_{i}\left(x_{j}\right)+x_{j}\right)} \geqslant \frac{P^{\prime}\left(m_{i}\left(x_{j}\right)+x^{*}\right)}{P\left(m_{i}\left(x_{j}\right)+x^{*}\right)} .
$$

From the strictly decreasing property of $P$ it follows then

$$
P\left(m_{i}\left(x_{j}\right)+x^{*}\right)+m_{i}\left(x_{j}\right) P^{\prime}\left(m_{i}\left(x_{j}\right)+x^{*}\right)-b^{\prime}\left(m_{i}\left(x_{j}\right)\right) \leqslant 0 .
$$

From Eq. (17) we get $m_{i}\left(x_{j}\right) \geqslant x^{*}$. Moreover the function $x P\left(x+x_{j}\right)-b(x)$ is strictly increasing on the interval $\left(0, m_{i}\left(x_{j}\right)\right)$. In particular for $\tilde{x}_{i}<x_{i}$ one obtains

$$
\tilde{\Pi}_{i}=\tilde{p} \tilde{x}_{i}-b\left(x_{i}\right)<\tilde{p} \tilde{x}_{i}-b\left(\tilde{x}_{i}\right)<p x_{i}-b\left(x_{i}\right)=\Pi_{i}
$$


Firm $i$ will make strictly lower profits. Analogue arguments for firm $j$.

\section{Main results}

Theorem 2 Let Assumptions 1, 2, 3 hold. Let $x^{*} \in[0,+\infty)$ solve Eq. (17). Denote by $\underline{k}:=\min \left\{k_{i}, k_{j}\right\}$ and $\bar{k}:=\max \left\{k_{i}, k_{j}\right\}$. If $\underline{k} \geqslant x^{*}$ then the Cournot outcome $\bar{x}_{i}=\bar{x}_{j}=x^{*}$ and $p_{i}=p_{j}=P\left(2 x^{*}\right)$ is the unique subgame perfect equilibrium for the full game. If $\bar{k} \leqslant x^{*}$ then firms set $\bar{x}_{i}=k_{i}, \bar{x}_{j}=k_{j}$ and $p_{i}=p_{j}=P\left(k_{i}+k_{j}\right)$.

Proof Let $\underline{k} \geqslant x^{*}$ then both firms know with certainty that the other firm's capacity level is at least $x^{*}$. Without loss of generality let $k_{i}>k_{j} \geqslant x^{*}$. To see why the Cournot outcome is a subgame perfect equilibrium for the full game assume that firm $j$ sets with certainty a production level equal to the Cournot level namely $x_{j}=x^{*}$, but firm $i$ sets with certainty a higher production level $x^{*}<x_{i} \leqslant k_{i}$. Theorem 1 a mixed equilibrium in prices $p$ exists in the second stage. Let $A=\left[p_{L}, p_{H}\right]$ with $p_{L}<p_{H}$ be the interval of active strategies in prices over which firm $i$ and $j$ will randomise according to distributions $\Phi_{i}(p)$ and $\Phi_{j}(p)$ respectively. We have shown that $\Phi_{i}\left(p_{H}\right)<1$ and $\Phi_{j}\left(p_{H}\right)=1$. The expected payoff of firm $i$ when it sets a production level higher than the Cournot level would be

$$
\mathbb{E} \Pi_{i}(p)=\left(1-\Phi_{j}(p)\right) \min \left\{p x_{i}, p D(p)\right\}+\Phi_{j}(p) \min \left\{p x_{i}, \max \left\{0, p\left(D(p)-x^{*}\right)\right\}\right\}-b\left(x_{i}\right) .
$$

If firm $i$ had not deviated from the Cournot level $x^{*}$ its profits would have been

$$
\Pi^{*}=\min \left\{p^{*} x^{*}, \max \left\{p^{*} D\left(p^{*}\right) / 2, p^{*}\left(D\left(p^{*}\right)-x^{*}\right)\right\}\right\}-b\left(x^{*}\right)
$$

where $p^{*}:=P\left(2 x^{*}\right)$ is the Cournot price. Therefore firm $i$ would have an incentive to deviate if and only if

$$
\mathbb{E} \Pi_{i}(p)-\Pi^{*} \geqslant 0, \forall p \in\left[p_{L}, p_{H}\right] .
$$

In particular at $p=p_{H}$ the expected payoff of firm $i$ is

$$
\mathbb{E} \Pi_{i}\left(p_{H}\right)=\min \left\{p_{H} x_{i}, \max \left\{0, p_{H}\left(D\left(p_{H}\right)-x^{*}\right)\right\}\right\}-b\left(x_{i}\right) .
$$

Notice that $D\left(p^{*}\right)=P^{-1}\left(p^{*}\right)=P^{-1}\left(P\left(2 x^{*}\right)\right)=2 x^{*}$ by definition of $D(p)$. This reduces (19) to $\Pi^{*}=p^{*} x^{*}-b\left(x^{*}\right)$ and therefore inequality (20) at $p=p_{H}$ becomes

$$
\min \left\{p_{H} x_{i}, \max \left\{0, p_{H}\left(D\left(p_{H}\right)-x^{*}\right)\right\}\right\}-p^{*} x^{*}+b\left(x^{*}\right)-b\left(x_{i}\right) \geqslant 0 .
$$

Realizing

$\min \left\{p_{H} x_{i}, \max \left\{0, p_{H}\left(D\left(p_{H}\right)-x^{*}\right)\right\}\right\}=\max \left\{0, \min \left\{p_{H} x_{i}, p_{H}\left(D\left(p_{H}\right)-x^{*}\right)\right\}\right\}$ we can rewrite the last inequality as

$$
\max \left\{-p^{*} x^{*}, \min \left\{p_{H} x_{i}-p^{*} x^{*}, p_{H}\left(D\left(p_{H}\right)-x^{*}\right)-p^{*} x^{*}\right\}\right\} \geqslant b\left(x_{i}\right)-b\left(x^{*}\right)>0
$$


where the positivity follows from the assumption that $b(x)$ is increasing in $x$. Indeed the assumption that $b^{\prime}(0)>0$ and $b(x)$ is convex i.e. $b^{\prime \prime}(x) \geqslant 0$ for all $x$ imply $b^{\prime}(x) \geqslant b^{\prime}(0)>0$ for all $x \geqslant 0$. This forces $p_{H} x_{i}>p^{*} x^{*}$ and $p_{H}\left(D\left(p_{H}\right)-x^{*}\right)>p^{*} x^{*}$. Clearly this implies that $p_{H} \neq p^{*}$. If $D\left(p_{H}\right)-x^{*}=x_{H}$ then last inequality can be writen as $p_{H} x_{H}>p^{*} x^{*}$. On the other hand $p_{H} x_{H}-b\left(x_{H}\right)<p^{*} x^{*}-b\left(x^{*}\right)$ implies $b\left(x_{H}\right)>b\left(x^{*}\right)$. Since $b(x)$ is increasing then $x_{H}>x^{*}$. From the law of demand then $P\left(x_{H}+x^{*}\right)<P\left(2 x^{*}\right)$ which is the same as $p_{H}<p^{*}$. There are two cases. First when $x_{i} \geqslant x_{H}$ then (22) simplifies to $p_{H} x_{H}-b\left(x_{i}\right) \geqslant p^{*} x^{*}-b\left(x^{*}\right)$. But $p_{H} x_{H}-b\left(x_{i}\right)<p_{H} x_{H}-b\left(x_{H}\right)<p^{*} x^{*}-b\left(x^{*}\right)$ therefore a contradiction. In the second case $x_{i}<x_{H}$ then (22) simplifies to $p_{H} x_{i}-p^{*} x^{*} \geqslant b\left(x_{i}\right)-b\left(x^{*}\right)$. Again from the law of demand $p_{i}:=P\left(x_{i}+x^{*}\right)>P\left(x_{H}+x^{*}\right)=p_{H}$ we get $p_{H} x_{i}-p^{*} x^{*}<p_{i} x_{i}-p^{*} x^{*}$. Hence $p_{i} x_{i}-p^{*} x^{*}>b\left(x_{i}\right)-b\left(x^{*}\right)$ and rearranging terms yields $p_{i} x_{i}-b\left(x_{i}\right)>p^{*} x^{*}-b\left(x^{*}\right)$. This is however impossible. Since both cases are exhausted this means the inequality (22) cannot hold true violating (20). Therefore firm $i$ has no incentive to increase its output above $x^{*}$. Now suppose that firm $i$ would have an incentive to deviate by setting an output level lower than the Cournot level i.e. $x_{i}<x^{*}$. If this is the case then from Lemma 1 in the second stage a pure strategy in prices is supported $p_{i}=p_{j}=P\left(x_{i}+x^{*}\right)$. Economic reason being that the output is too low for a price undercutting to take place from either firm. Hence a deviation from this pricing strategy would result in lower profits. Profits for firm $i$ would be $\Pi_{i}=p x_{i}-b\left(x_{i}\right)$. On the other hand by (17) we have $p^{*} x^{*}-b\left(x^{*}\right)>p x-b(x)$ for any other $x$ where $p:=P\left(x+x^{*}\right)$. In particular for $x_{i}<x^{*}$ we get $p^{*} x^{*}-b\left(x^{*}\right)>p x_{i}-b\left(x_{i}\right)$ implying $\Pi_{i}^{*}>\Pi_{i}$. Therefore if firm $i$ deviates it will lead to lower profits. This completes the argument when $\underline{k} \geqslant x^{*}$.

Now let $\bar{k} \leqslant x^{*}$. Then firms know with certainty that the other firm's actual capacity is not larger than the Cournot level of output. Hence for any realization $\left(x_{i}, x_{j}\right)$ from the first stage it is certain that $\max \left\{x_{i}, x_{j}\right\} \leqslant x^{*}$. By Lemma 1 then $p_{i}=p_{j}=P\left(x_{i}+x_{j}\right)$ would be supported as an equilibrium for the second stage. Let the strategy plans for firm $i$ and $j$ be

$$
S_{i}=\left\{\bar{x}_{i}=k_{i}, p_{i}=P\left(\bar{x}_{i}+x_{j}\right), \forall x_{j} \in\left[0, x^{*}\right]\right\}
$$

and

$$
S_{j}=\left\{\bar{x}_{j}=k_{j}, p_{j}=P\left(x_{i}+\bar{x}_{j}\right), \forall x_{i} \in\left[0, x^{*}\right]\right\} .
$$

To see why $S_{j}=B_{j}\left(S_{i}\right)$ and $S_{i}=B_{i}\left(S_{j}\right)$, where $B_{i}$ and $B_{j}$ are best response functions of firm $i$ and $j$ respectively, consider the end of the game. Profits for firm $i$ and $j$ would be $\bar{\Pi}_{i}=\bar{p} \bar{x}_{i}$ and $\bar{\Pi}_{j}=\bar{p} \bar{x}_{j}$ respectively where $\bar{p}:=P\left(\bar{x}_{i}+\bar{x}_{j}\right)$. Without loss of generality let firm $i$ have an incentive to deviate by setting another level of production $x_{i}<\bar{x}_{i}=k_{i}$, then its profits would be $\Pi_{i}=p x_{i}-b\left(x_{i}\right)$ with $p:=P\left(x_{i}+\bar{x}_{j}\right)$. Define the quantity $m\left(\bar{x}_{j}\right):=\arg \max _{x}\left\{x P\left(x+\bar{x}_{j}\right)-b(x)\right\}$. Since $m\left(\bar{x}_{j}\right) \in\left(0, X-\bar{x}_{j}\right)$ from the first order condition we get

$$
P\left(m\left(\bar{x}_{j}\right)+\bar{x}_{j}\right)+m\left(\bar{x}_{j}\right) P^{\prime}\left(m\left(\bar{x}_{j}\right)+\bar{x}_{j}\right)-b^{\prime}\left(m\left(\bar{x}_{j}\right)\right)=0 .
$$

Assumption $\bar{x}_{j}=k_{j}<x^{*}$ implies 


$$
P\left(m\left(\bar{x}_{j}\right)+x^{*}\right)+m\left(\bar{x}_{j}\right) P^{\prime}\left(m\left(\bar{x}_{j}\right)+x^{*}\right)-b^{\prime}\left(m\left(\bar{x}_{j}\right)\right)<0 .
$$

From the Eq. (17) we then obtain $m\left(\bar{x}_{j}\right)>x^{*}$ hence the function $x P\left(x+\bar{x}_{j}\right)-b(x)$ is strictly increasing on the interval $\left(0, m\left(\bar{x}_{j}\right)\right)$ and in particular for $\bar{x}_{i}>x_{i}$ we have

$$
x_{i} P\left(x_{i}+\bar{x}_{j}\right)-b\left(x_{i}\right)<\bar{x}_{i} P\left(\bar{x}_{i}+\bar{x}_{j}\right)-b\left(\bar{x}_{i}\right)=\bar{\Pi}_{i} .
$$

So if firm $i$ deviates it will make striclty lower profits. This completes the proof.

Proposition 1 The Cournot outcome can be supported as an imperfect equilibrium of the full game when $\underline{k} \geqslant x^{*}$.

Proof For simplicity assume $b(x)=0$. Let $x^{*} \in[0,+\infty)$ satisfy Eq. (17). If $k \geqslant x^{*}$ then both firms know with certainty that the other firm's capacity level is at least $x^{*}$. Consider the following strategy plans for firm $i$

$$
S_{i}=\left\{\bar{x}_{i}=x^{*}, p_{i}=P\left(2 x^{*}\right) \text { if } \bar{x}_{j}=x^{*} ; \bar{x}_{i}=x^{*}, p_{i}=0, \text { if } \bar{x}_{j} \neq x^{*}\right\}
$$

and similarly for firm $j$

$$
S_{j}=\left\{\bar{x}_{j}=x^{*}, p_{j}=P\left(2 x^{*}\right) \text { if } \bar{x}_{i}=x^{*} ; \bar{x}_{j}=x^{*}, p_{j}=0 \text {, if } \bar{x}_{i} \neq x^{*}\right\} .
$$

Denote the best response of firm $i$ to a strategy played by firm $j$ by $B_{i}\left(S_{j}\right)$. We claim that $B_{i}\left(S_{j}\right)=S_{i}$ and $B_{j}\left(S_{i}\right)=S_{j}$. Let firm $i$ deviate from $S_{i}$ by setting an output level $x_{i} \neq x^{*}$. When $\left(S_{i}, S_{j}\right)$ is played the profits to firm $i$ and $j$ are $\bar{\Pi}_{i}=\bar{\Pi}_{j}=p^{*} x^{*}$ where $p^{*}:=P\left(2 x^{*}\right)$. If firm $i$ deviates then firm $j$ would set a zero price and firm $i$ would be faced with a residual demand $D(p)-x^{*}$ on which it can act as a monopoly. Denote by $x:=D(p)-x^{*}$ then firm $i$ 's profits $\Pi_{i}(x)=x P\left(x+x^{*}\right)$ is maximized for the quantity $\hat{x}$ solving the equation

$$
P\left(\hat{x}+x^{*}\right)+\hat{x} P^{\prime}\left(\hat{x}+x^{*}\right)=0 .
$$

On the other hand in view of equation (17) for $b(x) \equiv 0$ we have

$$
P\left(2 x^{*}\right)+x^{*} P^{\prime}\left(2 x^{*}\right)=0 .
$$

These last two equations and Assumption 1 imply $\hat{x}=x^{*}$. Therefore if $x_{i} \neq x^{*}$ then either firm $i$ would make strictly less profits when producing $x_{i}<x^{*}$ or else it would make the same profit $p^{*} x^{*}$ but with the amount of stock $x_{i}-x^{*}>0$ remaining unsold. So firm $i$ would have no incentive to deviate from $\bar{x}_{i}=x^{*}$. Note that the set of strategies $\left(S_{i}, S_{j}\right)$ in (23)-(24) does not constitute a perfect equilibrium because the threats are not credible.

Theorem 3 Suppose $k<x^{*}<\bar{k}$ and that a pure strategy is supported in the first stage of the game. Then both firms will produce at their full capacities provided their capacity levels are sufficiently small. 
Proof Without loss of generality let $k_{j}<x^{*}<k_{i}$ and that $k_{i}, k_{j}$ are sufficiently small in a sense to be made precise later. Assume that a pure strategy $\left(\bar{x}_{i}, \bar{x}_{j}\right)$ is supported in the first stage of the game but $\bar{x}_{i} \leqslant x^{*}$ or $\bar{x}_{j}<k_{j}<x^{*}$.

First consider $\bar{x}_{i}<x^{*}$ and $\bar{x}_{j} \leqslant k_{j}$. Since $\max \left\{\bar{x}_{i}, \bar{x}_{j}\right\} \leqslant x^{*}$ by Lemma 1 a pure strategy in prices $p_{i}=p_{j}=P\left(\bar{x}_{i}+\bar{x}_{j}\right)$ is supported in the second stage of the game. The profit to firm $i$ and $j$ would then be $\Pi_{i}=p \bar{x}_{i}-b\left(\bar{x}_{i}\right)$ and $\Pi_{j}=p \bar{x}_{j}-b\left(\bar{x}_{j}\right)$ respectively. By Assumption 1 it follows that for a fixed $y$ the function $x P(x+y)-b(x)$ has a unique maximizer $m(y) \in(0, X-y)$. In particular this means that for $y=\bar{x}_{j}$ there exists a unique $m_{i}\left(\bar{x}_{j}\right) \in\left(0, X-\bar{x}_{j}\right)$. The first order condition implies

$$
P\left(m_{i}\left(\bar{x}_{j}\right)+\bar{x}_{j}\right)+m_{i}\left(\bar{x}_{j}\right) P^{\prime}\left(m_{i}\left(\bar{x}_{j}\right)+\bar{x}_{j}\right)-b^{\prime}\left(m_{i}\left(\bar{x}_{j}\right)\right)=0 .
$$

On the other hand from the assumption $k_{j}<x^{*}$ we obtain $\bar{x}_{j}<x^{*}$. But $P(x)$ is strictly decreasing and a log-concave function of $x$ so

$$
P\left(m_{i}\left(\bar{x}_{j}\right)+x^{*}\right)+m_{i}\left(\bar{x}_{j}\right) P^{\prime}\left(m_{i}\left(\bar{x}_{j}\right)+x^{*}\right)-b^{\prime}\left(m_{i}\left(\bar{x}_{j}\right)\right)<0
$$

This inequality together with (17) implies $m_{i}\left(\bar{x}_{j}\right)>x^{*}$. This means that the function $x P\left(x+\bar{x}_{j}\right)-b(x)$ is increasing on the interval $\left(0, m_{i}\left(\bar{x}_{j}\right)\right)$ and has a positive slope at $x=x^{*}$. So if firm $j$ produces $\bar{x}_{j}$ then firm $i$ by increasing its production to a level $x_{i}>\bar{x}_{i}$ yet $x_{i} \leqslant x^{*}$ increases its profits.

Now assume that $\bar{x}_{i}=x^{*}$ and $\bar{x}_{j}<k_{j}$. Again by Lemma 1 in the second stage the equilibrium price would be $p_{i}=p_{j}=P\left(x^{*}+\bar{x}_{j}\right)$. Similar calculations show that $m_{j}\left(x^{*}\right) \geqslant x^{*}$ and that $x P\left(x^{*}+x\right)-b(x)$ is increasing on the interval $\left(0, m_{j}\left(x^{*}\right)\right)$. Assumption $k_{j}<x^{*}$ then implies that if firm $j$ increases its output to $x_{j}=k_{j}$ then it will increase its profits under the new equilibrium price $P\left(x^{*}+k_{j}\right)$. So firm $j$ would choose to set $\bar{x}_{j}=k_{j}$ in the first stage violating the assumption $\bar{x}_{j}<k_{j}$. Therefore we must have $\bar{x}_{i} \geqslant x^{*}$ and $\bar{x}_{j}=k_{j}$.

Under the additional assumption $k_{i} \leqslant m_{i}\left(k_{j}\right)$ where

$$
m_{i}\left(k_{j}\right)=\arg \max _{x_{i}}\left\{x_{i} P\left(x_{i}+k_{j}\right)-b\left(x_{i}\right)\right\}, \quad \text { for } i \neq j
$$

we claim that firms $i$ and $j$ will set a precommitment level of $\bar{x}_{i}=k_{i}$ and $\bar{x}_{j}=k_{j}$. First we show that for any $\bar{x}_{i}$ such that $x^{*} \leqslant \bar{x}_{i} \leqslant k_{i}$ in the second stage an equilibrium price $p=P\left(\bar{x}_{i}+k_{j}\right)$ is supported. Clearly neither firm will set a lower price as it leads to strictly lower profits. Without loss of generality say firm $i$ sets higher price $\tilde{p}>p$. Then its profits would be

$$
\tilde{\Pi}_{i}=\max \left\{0, \min \left\{\tilde{p} \bar{x}_{i}, \tilde{p}\left(D(\tilde{p})-k_{j}\right)\right\}\right\}-b\left(\bar{x}_{i}\right) .
$$

Let $\tilde{x}_{i}:=D(\tilde{p})-k_{j}$ then by law of demand $D(\tilde{p})<D(p)$ implies $\tilde{x}_{i}<\bar{x}_{i}$. So $\tilde{\Pi}_{i}=\tilde{p} \tilde{x}_{i}-b\left(\bar{x}_{i}\right)$. The function $x P\left(x+k_{j}\right)-b(x)$ attains its maximum at a unique point $m_{i}\left(k_{j}\right)$. Assumption $k_{j}<x^{*}$, first order condition for $m_{i}\left(k_{j}\right)$ and log-concavity of $P(x)$ imply $m_{i}\left(k_{j}\right)>x^{*}$. In particular it follows that $x P\left(x+k_{j}\right)-b(x)$ is strictly increasing on the interval $\left(0, m_{i}\left(k_{j}\right)\right)$. Provided $k_{i} \leqslant m_{i}\left(k_{j}\right)$ then from $\tilde{x}_{i}<\bar{x}_{i}<k_{i}$ one obtains 


$$
\tilde{\Pi}_{i}=\tilde{p} \tilde{x}_{i}-b\left(\bar{x}_{i}\right)<\tilde{p} \tilde{x}_{i}-b\left(\tilde{x}_{i}\right)<p \bar{x}_{i}-b\left(\bar{x}_{i}\right)=\Pi_{i} .
$$

Hence firm $i$ would not set a higher price in the second stage. Likewise suppose firm $j$ has an incentive to increase its price to $\tilde{p}>p$ then similar calculations as for firm $i$ show $\tilde{x}_{j}<k_{j}$ and $\tilde{\Pi}_{j}=\tilde{p} \tilde{x}_{j}-b\left(k_{j}\right)$. Note that $\tilde{p}=P\left(\bar{x}_{i}+\tilde{x}_{j}\right)$. Since $\bar{x}_{i} \geqslant x^{*}$ then $m_{j}\left(\bar{x}_{i}\right) \leqslant x^{*}$. On the other hand one can show that $m_{j}\left(k_{i}\right) \leqslant m_{j}\left(\bar{x}_{i}\right)$ for any $\bar{x}_{i} \in\left[x^{*}, k_{i}\right]$. Assumption $k_{j} \leqslant m_{j}\left(k_{i}\right)$ implies $k_{j} \leqslant m_{j}\left(\bar{x}_{i}\right)$. Since $\tilde{x}_{j}<k_{j}$ then

$$
\tilde{\Pi}_{j}=\tilde{p} \tilde{x}_{j}-b\left(k_{j}\right)<\tilde{p} \tilde{x}_{i}-b\left(\tilde{x}_{j}\right)<p k_{j}-b\left(k_{j}\right)=\Pi_{i}
$$

Therefore firm $j$ would not deviate from the price $p=P\left(\bar{x}_{i}+k_{j}\right)$ in the second stage. In particular this means that firm $i$ knows that for any level $\bar{x}_{i} \in\left[x^{*}, k_{i}\right]$ a pure strategy in prices will take place in the second stage. Assumption $k_{i} \leqslant m_{i}\left(k_{j}\right)$ then implies that by setting $\bar{x}_{i}=k_{i}$ firm $i$ would indeed maximize its profits.

Funding Open Access funding enabled and organized by Projekt DEAL..

\section{References}

Beckmann, M.J.: (with the assistance of Dieter Hochstadter). In: Rudolf Henn (ed.) Edgeworth-Bertrand Duopoly Revisited. Operations Research- Verfahren, vol. III. Sonderdruck Verlag, Anton Hain, Meisenheim (1965)

Davidson, C., Deneckere, R.: Long-term competition in capacity, short-run competition in price, and the Cournot model. Rand J. Econ. 17(3), 404-415 (1986)

de Frutos, M., Fabra, N.: Endogenous capacities and price competition: the role of demand uncertainty. Int. J. Ind. Org. 29(4), 399-411 (2011)

Deneckere, R.J., Kovenock, D.: Bertrand-edgeworth duopoly with unit cost asymmetry. Econ. Theor. 8(1)

Edgeworth, F.Y.: The pure theory of monopoly. Papers Relating to Political Economy, I. (London: MacMillan), 111- 142 (1925)

Fudenberg, D., Tirole, J.: Game Theory. MIT Press, New York (1991)

Gabszewicz, J., Poddar, S.: Demand fluctuations and capacity utilization under duopoly. Econ. Theor. 10(1), 131-146 (1997)

Hviid, M.: Sequential capacity and price choices in a duopoly model with demand uncertainty. J. Econ. 51(2), 121-144 (1990)

Hviid, M.: Capacity constrained duopolies, uncertain demand and non-existence of pure strategy equilibria. Eur. J. Polit. Econ. 7, 183-190 (1991)

Jara-Moroni, P.: The Cournot outcome as the result of price competition. halshs: 00587866 (2011)

Kreps, D.M., Scheinkman, J.A.: Quantity precommitment and Bertrand competition yield Cournot outcomes. Bell J. Econ. 14(2), 326-337 (1983)

Levitan, R., Shubik, M.: Price duopoly and capacity constraints. Int. Econ. Rev. 13(1), 111-122 (1972)

Madden, P.: Elastic demand, sunk costs and the Kreps-Scheinkman extension of the Cournot model. Econ. Theor. 12(1), 199-212 (1998)

Nie, P., Chen, Y.: Duopoly competitions with capacity constrained input. Econ. Model. 29(5), 1715-1721 (2012)

Osborne, M.J., Pitchik, C.: Price competition in a capacity-constrained duopoly. J. Econ. Theory 38(2), 238-260 (1986)

Shubik, M.: Strategy and Market Structure. Wiley, New York (1959)

Publisher's Note Springer Nature remains neutral with regard to jurisdictional claims in published maps and institutional affiliations. 